\title{
RISK-BASED PRIORITY SCORING FOR BROOKHAVEN NATIONAL LABORATORY ENVIRONMENTAL RESTORATION PROGRAMS
}

S. C. Morris and A. F. Meinhold

May 1995

\author{
Biomedical and Environmental \\ Assessment Group \\ Analytical Sciences Division
}

DEPARTMENT OF APPLIED SCIENCE

BROOKHAVEN NATIONAL LABORATORY UPTON, LONG ISLAND, NEW YORK 11973 


\section{DISCLAIMER}

This report was prepared as an account of work sponsored by an agency of the United States Government. Neither the United States Government nor any agency thereof, nor any of their employees, nor any of their contractors, subcontractors, or their employees, makes any warranty, express or implied, or assumes legal liability or responsibility for the accuracy, completeness, or usefulness of any information, apparatus, product, or process disclosed, or represents that its use would not infringe privately owned rights. Reference herein to any specific commercial product, process, or service by trade name, trademark, manufacturer, or otherwise does not necessarily constitute or imply its endorsement, recommendation or favoring by the United States Government or any agency, contractor, or sukicontractor thereof. The views and opinions of authors expressed herein do not necessarily state or reflect those of the United States Government or any agency, contractor or subcontractor thereof. 


\section{DISCLAIMER}

Portions of this document may be illegible in electronic image products. Images are produced from the best available original document. 


\section{RISK-BASED PRIORITY SCORING FOR BROOKHAVEN NATIONAL LABORATORY ENVIRONMENTAL RESTORATION PROGRAMS}

S.C. Morris and A.F. Meinhold

May 1995

BIOMEDICAL AND ENVIRONMENTAL ASSESSMENT GROUP ANALYTICAL SCIENCES DIVISION DEPARTMENT OF APPLIED SCIENCE BROOKHAVEN NATIONAL LABORATORY UPTON, NY 11973

Under Contract No. DE-ACO2-76CH00016 with the U. S. Department of Energy 


\begin{abstract}
This report describes the process of estimating the risk associated with environmental restoration programs under the Brookhaven National Laboratory Office of Environmental Restoration. The process was part of an effort across all Department of Energy facilities to provide a consistent framework to communicate risk information about the facilities to senior managers in the DOE Office of Environmental Management to foster understanding of risk activities across programs. The risk evaluation was a qualitative exercise. Categories considered included: public health and safety; site personnel safety and health; compliance; mission impact; cost-effective risk management; environmental protection; inherent worker risk; environmental effects of clean-up; and social, cultural, political, and economic impacts.
\end{abstract}




\section{ACKNOWLEDGMENTS}

The authors acknowledge the cooperation, assistance, and support of Bill Gunther, Head of OER; Project Engineers Jim Brower, Bob Litzke, Tom Burke, A.M. Topé, and Skip Medeiros; Michael Hauptman, and especially Bal Patel, who participated in all the interviews and acted as our principal contact at OER. 


\section{TABLE OF CONTENTS}

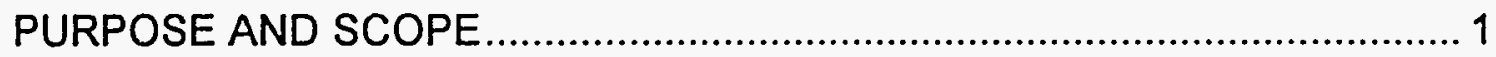

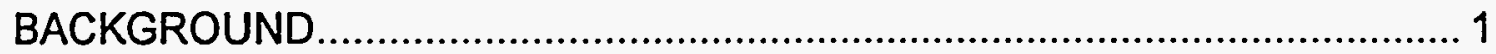

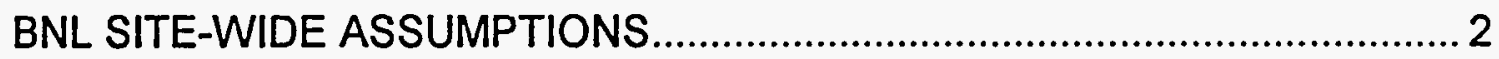

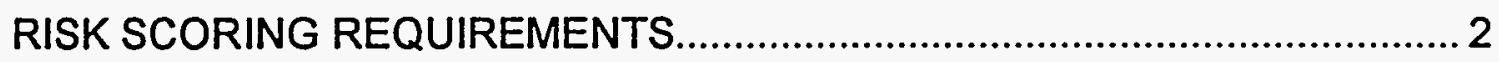

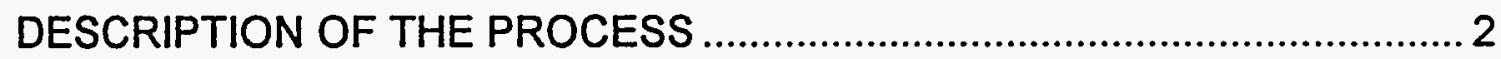

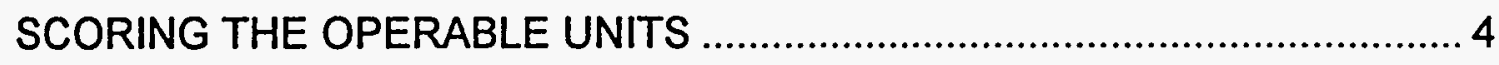

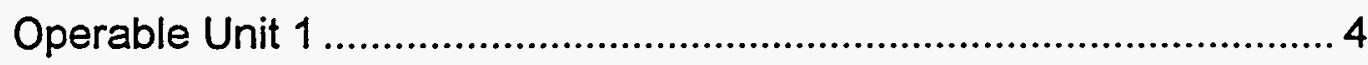

Inherent Worker Risk ............................................................... 4

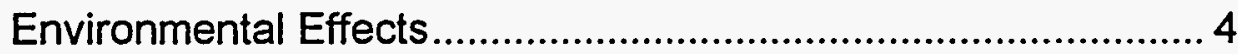

Social/Cultural/Political/Economic Impacts............................... 5

Public Safety and Health ......................................................... 5

Site Personnel Safety and Health............................................. 5

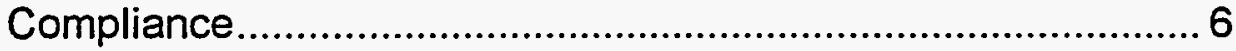

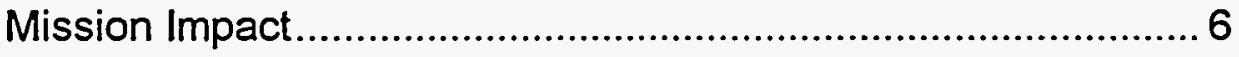

Cost-Effective Management..................................................... 6

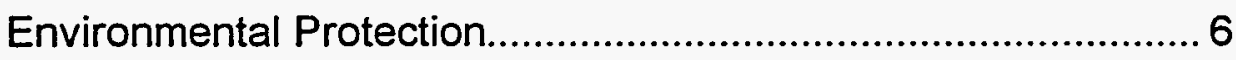

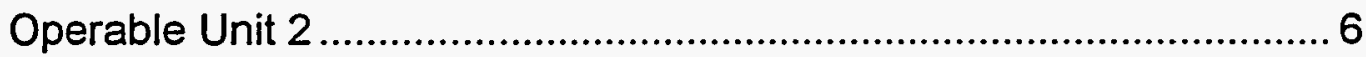

Operable Unit 2: Severe Scenario............................................. 7

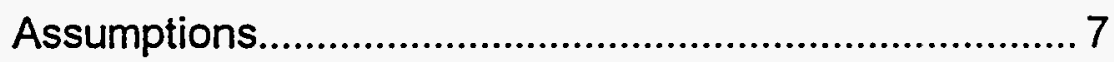

Inherent Worker Risk ................................................... 7

Environmental Effects ..................................................... 7

Social/Cultural/Political/Economic Impacts ...................... 7

Public Safety and Health............................................... 7

Site Personnel Safety and Health................................... 8

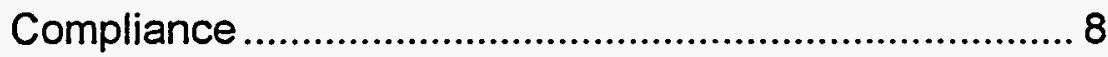

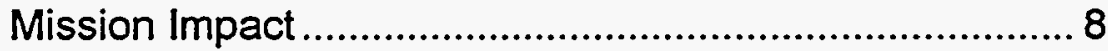

Cost-Effective Management ............................................. 8

Environmental Protection............................................ 8

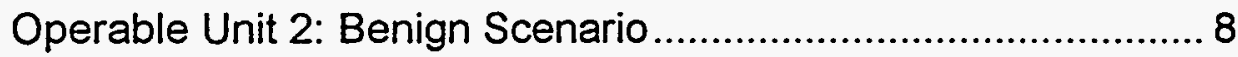




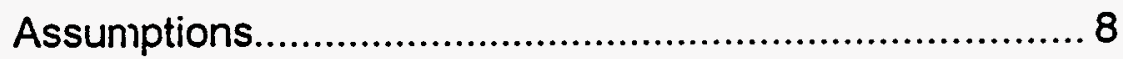

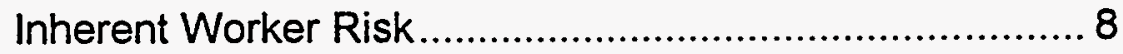

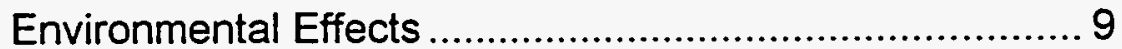

Social/Cultural/Political/Economic Impacts ...................... 9

Public Safety and Health............................................. 9

Site Personnel Safety and Health .................................. 9

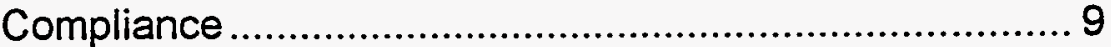

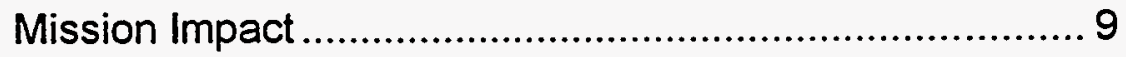

Cost-Effective Management........................................... 9

Environmental Proiection............................................... 9

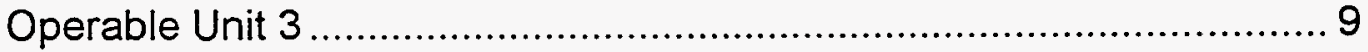

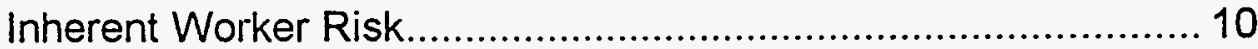

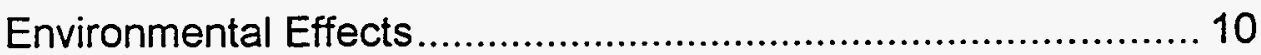

Social/Cultural/Political/Economic Impacts................................ 10

Public Safety and Health ........................................................ 10

Site Personnel Safety and Health.............................................. 10

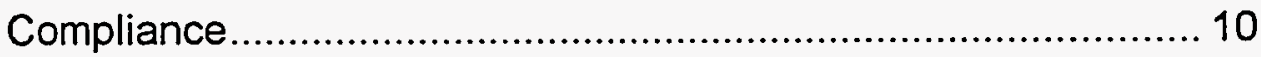

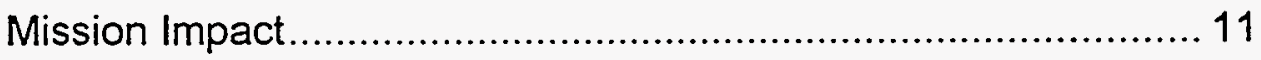

Cost-Effective Management.................................................... 11

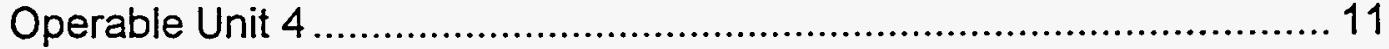

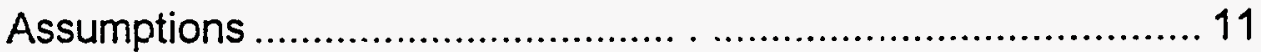

Inherent Worker Risk ........................................................... 11

Environmental Effects............................................................. 11

Social/Cultural/Political/Economic Impacts.............................. 12

Stakeholder/Public Perceptions.............................................. 12

Public Safety and Health ...................................................... 12

Site Personnel Safety and Health............................................. 12

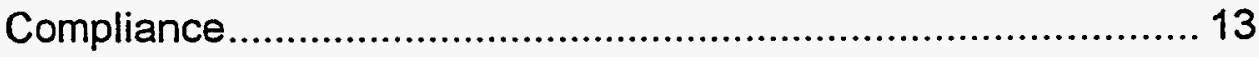

Mission Impact...................................................................... 13

Cost-Effective Management................................................... 13

Environmental Protection....................................................... 13 


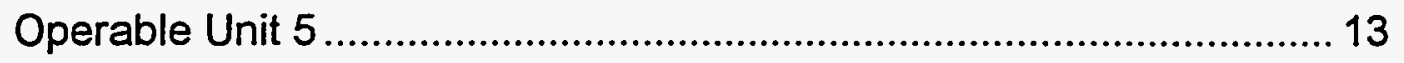

Operable Unit 5: Severe Scenario.............................................. 13

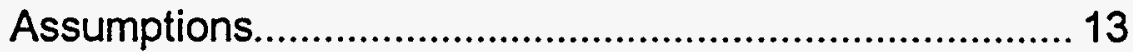

Inherent Worker Risk..................................................... 14

Environmental Effects .................................................... 14

Social/Cultural/Political/Economic Impacts ...................... 14

Public Safety and Health............................................... 14

Site Personnel Safety and Health ................................... 14

Compliance ................................................................... 14

Mission Impact ............................................................... 15

Cost-Effective Management.......................................... 15

Environmental Protection................................................ 15

Operable Unit 5: Benign Scenario ............................................. 15

Inherent Worker Risk .................................................. 15

Environmental Effects .................................................. 15

Social/Cultural/Political/Economic Impacts ...................... 15

Stakeholder/Public Perceptions ....................................... 15

Public Safety and Health.............................................. 15

Site Personnel Safety and Health ................................... 15

Compliance ................................................................... 16

Mission Impact ................................................................ 16

Cost-Effective Management.......................................... 16

Environmental Protection.................................................. 16

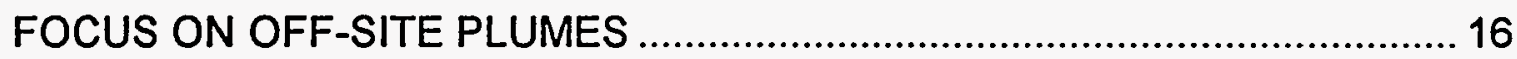

Consistent Assumptions for Off-site Plumes ....................................... 16

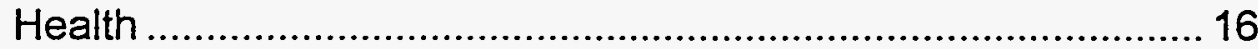

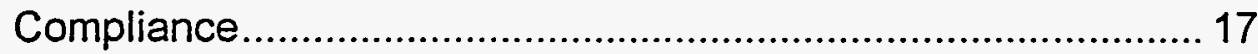

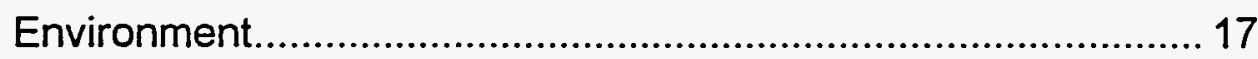

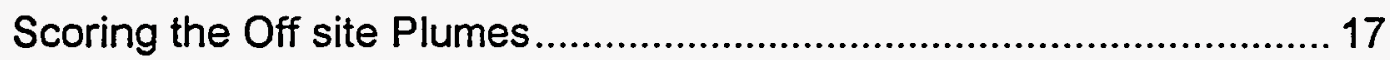

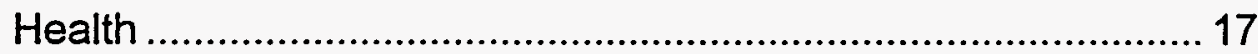

Environmental Impact ........................................................... 17 
INTERNAL CONSISTENCY CHECK OF OPERABLE UNIT

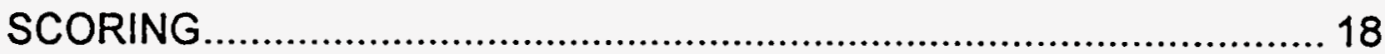

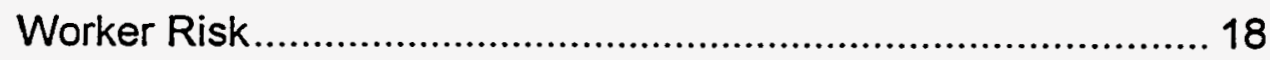

Environmental Effects.......................................................... 18

Social/Cultural/Political/Economic ........................................... 18

Public Health and Safety .................................................... 18

Site Personnel Safety and Health............................................ 18

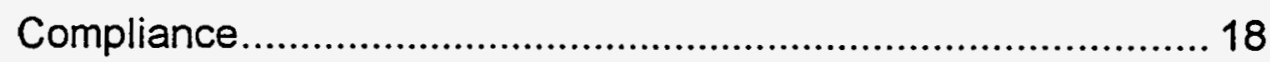

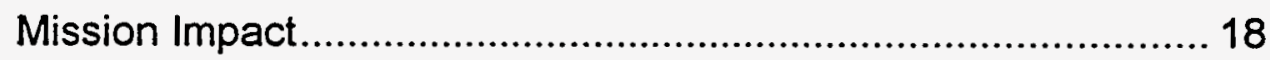

Cost Effective Management................................................... 18

Environmental Protection.......................................................... 19

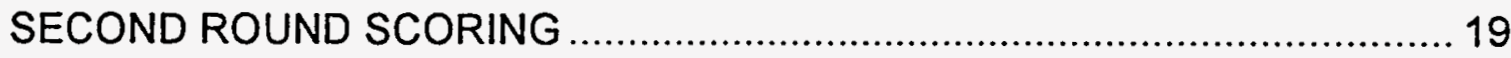

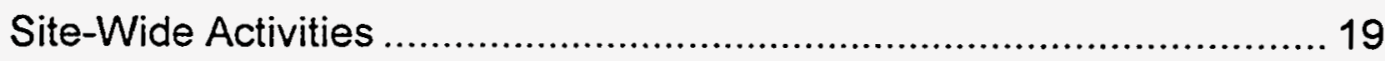

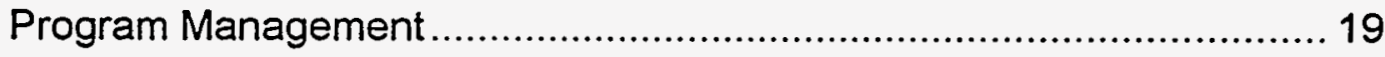

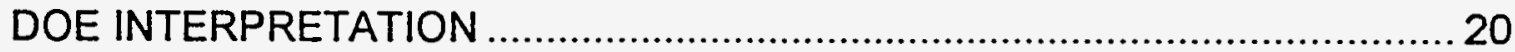

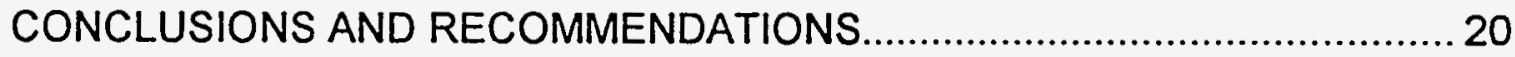

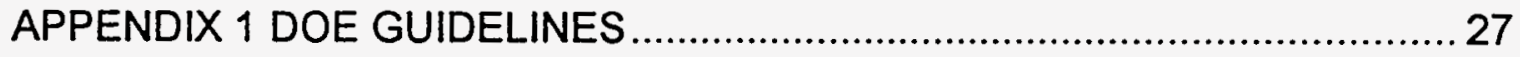

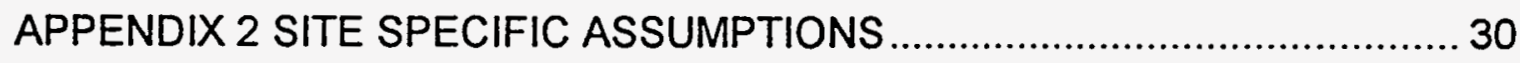

APPENDIX 3 COMMENTS ON THE RISK SCORING PROCESS .................. 38

APPENDIX 4. INCORPORATION OF "SPRAY AERATION" INTO ADS 2310 RISK DATA SHEETS …................................................................ 42 


\section{TABLES AND FIGURES}

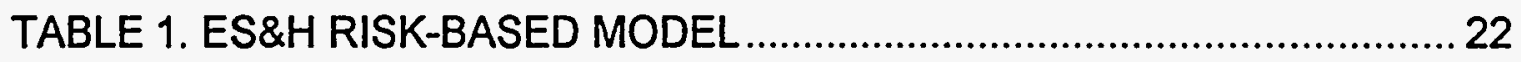

TABLE 2. SUMMARY OF SCORES BY OPERABLE UNIT...........................23

TABLE 3. SUMMARY OF "BENIGN" AND "SEVERE" SCORES, OU $4 \& 5 \ldots . .24$

TABLE 4. DOE INTERPRETATION OF RISK SCORES .................................25

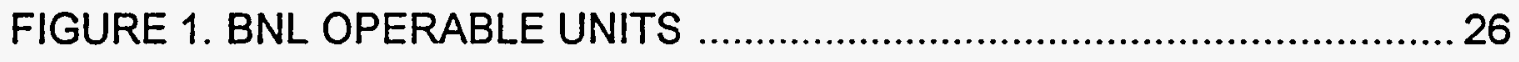




\section{PURPOSE AND SCOPE}

The Department of Energy (DOE) was required by Congress to review its compliance agreements and submit a report by June 30,1995. The report was to estimate the risk to health and safety of individual members of the public that would be addressed by cleanup activities, the health and safety effect of implementing the compliance agreements, and the associated costs. As part of this effort, the DOE Office of Integrated Risk Management tasked the Field Offices to provide information on risks using a modified form of a risk-based priority model developed by the DOE Office of Environmental Safety and Health. Guidance in developing the scores was provided by DOE (Appendix 1). Examples of the Risk Data Sheets and the Qualitative Risk Matrix used in this model are provided in Appendix 1.

Several organizations within Brookhaven National Laboratory (BNL) were required to score their programs. Participants in the process included USDOE Brookhaven Area Office, Director's Office, Office of Environmental Restoration, Safety and Environmental Protection Division, and the Department of Applied Science. This report describes the scoring for the Office of Environmental Restoration (OER), its basis and documentation.

In addition to the risk scoring, considerable additional information on budgets, program description, and other information was required to be reported. These items were done by the OER Project Engineers and/or administrative staff.

\section{BACKGROUND 1}

While risk is one of many factors used in making management decisions, it is important as a priority-setting tool. Because detailed risk information available at DOE laboratories was not available in a form useful to senior DOE management, a consistent, DOE-wide framework for capturing, reporting, and communicating summary level risk information was developed. Example questions typical of those confronting DOE management include:

Are Environmental Management activities addressing significant risks?

Do activities required by compliance agreements address significant risks?

Do the proposed activities inherently introduce risks to site workers or the environment that exceed existing risks?

\footnotetext{
${ }^{1}$ Material in this section was takein from "Risiks and the Risk Debate: Searching for Common Ground, The First Step", Vol. III, Appendix C (Draft), US DOE Office of Environmental Management, Washington, DC, June 1995.
} 
The DOE Office of Environmental Management organized a Risk Team that developed procedures and worked with field personnel to evaluate the Environmental Management program using the Activity Data Sheets and the existing management process. Activity Data Sheets are the principal planning and budget informational link between the Environmental Management field and headquarters organizations. The Risk Data Sheet survey instrument was developed by modifying the Environmental, Safety and Health Management Plan activity evaluation process to collect information and put in the Qualitative Risk Matrix, the evaluation tool. A pilot test of the instrument was conducted at the Nevada Test Site. Risk Data Sheets were established for each activity or group of similar activities with the same risk, e.g., operable unit, and these were provided to field offices to serve as the basis of their evaluation. Global assumptions were provided by Headquarters for guidance in the development of site-specific assumptions, establishing a consistent framework for evaluating each activity.

\section{BNL SITE SPECIFIC ASSUMPTIONS}

The site-specific assumptions that form the basis of the BNL scoring were developed with input from all of the participating BNL organizations. These include assumptions related to mission objectives, future land use, institutional control, and environmental restoration and waste management programs. These assumptions are given in Appendix 2.

\section{RISK SCORING REQUIREMENTS}

There were two parts to the scoring. The first part involved scoring of inherent worker risk and environmental effects during the cleanup and the social, cultural, political and economic impact of completing or not completing the activity. The second part, the Risk Matrix, involved scoring a number of categories before and after cleanup. These categories were Public Safety and Health, Site Personnel Safety and Health, Compliance, Mission Impact, Costeffective Risk Management, and Environmental Impact. Table 1 shows the categories in the risk matrix and the levels of impact and likelihood of occurrence for each potential score. A description of the categories and the likelihood levels is provided in Appendix 1. Both sections required scoring of the level of impact and the likelihood of occurrence.

\section{DESCRIPTION OF THE PROCESS}

The process began with a meeting of all BNL participants. At this meeting a general strategy was developed that the scoring would be at the level of 
"Activity Data Sheets," i.e., projects that were separately budgeted. In the case of OER, this meant that scoring was done at the level of an Operable Unit. It was decided that the element in the operable unit that had the highest risk would be the basis for the "before" score and that the element with the highest risk after cleanup would be the basis for the "after" score.

Within OER, the process began by interviewing the Project Engineer for each Operable Unit. The interviews included an explanation of the process; some general discussion of risk, soliciting a description of each element of the Operable Unit; the status of the work on that unit; and the kind of cleanup activities that were anticipated. The focus then turned to the scoring. The scoring sheets and the definitions of each possible score were explained. Example situations provided in the DOE guidance were read. The appropriate score was then elicited from the Project Engineer. A statement was elicited from the Project Engineer in justification of the score. In a few cases in the later interviews, it was immediately apparent that some scores were inconsistent with scores given by Project Engineers earlier for similar situations. There was some discussion of the comparison and in some cases the Project Engineer decided to change their score while in other cases the inconsistency was left to be resolved later.

A written draft of the scores and the supporting paragraphs was provided to the Project Engineer the next day for review.

Three of the operable units involved ground-water plumes that were potentially off-site. A further interview was held with Michael Hauptman, the project engineer responsible for the overall view of the off-site plumes. This interview involved the same overview and discussion phase, but then focused on reviewing the scores obtained from the individual Project Engineers.

A chart was prepared to facilitate comparison of the scores among the Operable Units. The scores and supporting paragraphs were reviewed for consistency. Some paragraphs were revised to reflect common wording for the same risks in different Operable Units. Some possible changes in scores were identified where different scores were assigned to similar risks in different Operable Units. At this review, two areas were identified for further attention; both involved off-site ground water contamination. First was the need to develop a common set of assumptions associated with off-site plumes for all Operable Units affected. Second was the need for a decision on how to score the environmental impact of off-site plumes. The latter was necessary because of a conflict between the definitions and the example in the DOE guidance.

A briefing was then given to $W$. Gunther, Head of OER, describing what had been done, presenting the original scores and the recommended changes and the proposed common assumptions and scoring approach for off-site plumes. The recommendations were approved. 
In a 2-day session, all the BNL organizations involved in the scoring presented their scores for review. A few scores were revised as a result of comments received during the review.

The scores, justification comments, and other information were entered into the DOE forms and transmitted electronically.

After the process was completed, a request came from the Chicago Operations Office to score Site-wide activities and Program Management, although the initial guidance had been to exclude these. The scoring process was repeated for these programs.

\section{SCORING THE OPERABLE UNITS}

The Operable Units scored in this initial exercise include OU-1, OU-2, OU-3, OU-4 and OU-5 (Figure 1). The basis of the score and likelihood category for each category is given below by Operable Unit. Tables 2 and 3 summarize the final scores.

\section{Operable Unit 1}

OU-1 includes the southern tritium plume, Glass Holes, Spray Aeration, Upland Recharge Area, the hazardous waste management facility, the EDB ground water contamination, and Recharge basin HS.

\section{Inherent Worker Risk}

The most significant worker risk would be an explosion resulting from disturbing unknown explosive mixtures in glass containers in the chemical holes. This risk is aggravated by the need for workers to wear level $B$ protection suits before entering these trenches. These suits lead to awkwardness in handling materials. This was judged to pose a risk of $2 \mathrm{C}$, greater than a $1 \%$ chance of a critical accident. In the final BNL review session, it was decided that this situation fit the description of a catastrophic risk; the score was increased to $1 \mathrm{C}$. A secondary source of risk is associated with opening up intact bottles from the chemical holes to take samples. It may be possible to avoid these risks through the use of robotics. Other worker risks throughout OU-1 would be routine construction accidents and the risk of Lyme disease from tick bites.

\section{Environmental Effects}

Possible breakage of glass containers in the process of excavating and emptying the chemical (glass) holes could significantly contaminate the ground water. This was judged to score $2 \mathrm{~B}$. Other operations in excavating the glass holes and other components of OU-1 involve minor, short-term and localized (but certain) environmental damage to the terrestrial ecosystem leading to a score of $3 \mathrm{~A}$. 


\section{Social/Cultural/Political/Economic impacts}

It is believed that contaminated ground water plumes from as many as four areas of concern underlie off-site property. Some of this property is currently residential and other parts are ripe for development. Significant economic impact could be incurred by real estate values decreasing due to fear of contamination, even if it is below drinking water levels. To some extent, these concerns already exist. They are likely to be accentuated if subsequent measurements demonstrate more extensive contamination. These economic impacts could quickly expand to social and political impacts. There already exists a high level of political interest as measured by the number and interest of civic and other groups. (Score $=2 \mathrm{~A}$ )

\section{Public Safety and Health}

Measurements at test wells on site, near the site boundary, and in drinking water wells and plume modeling suggest that contaminants have migrated off-site, possibly in four separately identifiable plumes (plumes from the hazardous waste management area, the current landfill, the former landfill, and the chemical holes). These plumes may already underlie a residential area served by private wells. Cnly a few off-site measurements are currently above drinking water standards, and it is not proven these stem from the site. Some off-site measurements of VOCs have been found by the Suffolk County Health Department to have originated from a non-BNL plume. Modeling suggests that the BNL plumes may run 30-50 feet below the level at which the wells are screened. There was judged to be a greater than $10 \%$ probability that siterelated contamination above drinking water standards will be demonstrated by further measurements or that, were no further action taken, concentrations in these wells would exceed drinking water standards at some point in the future. Recommended score is $2 \mathrm{~B}$ (more than $10 \%$ probability of excessive exposure).

Given that the anticipated action is taken, after 10 years of pump-andtreat, it was judged that sufficient improvement will be achieved to justify a score of $3 D$, i.e., low probability of moderate to low level exposure.

Site Personnel Safety and Health

Little or no opportunity exists for exposure to site personnel. The worst (unlikely) case would be that hikers or joggers would somehow get into the waste management area and have a small radiation exposure. There is no risk of chemical exposure. This risk was judged to be 7D, negligible with low probability.

Since 7D is the lowest possible score, it remains the same after remediation action. 


\section{Compliance}

"No action" would be in direct violation of the Compliance Agreement and would lead to violation of state and local law. This was scored $8 \mathrm{~A}$, a virtual certainty of major noncompliance.

After remediation, compliance was judged to be $10 \mathrm{C}$, a medium (1-10\%) risk of marginal noncompliance. This risk is assigned because existing technologies are unable to clean up the ground water to drinking water standards from levels that may exist.

\section{Mission Impact}

While lack of remediation would have no direct impact on BNL operations or other DOE missions, public outrage could overflow in a way that would affect R\&D programs. This was scored $13 \mathrm{C}$, a medium (1-10\%) risk of a moderate negative impact (the lowest category).

After remediation, the risk score was reduced to 13D, a low risk of a moderate negative impact (the lowest score).

\section{Cost-Effective Management}

Failure to implement the line item to cap the landfill would result in further degradation of ground water. The need to remedy this at a later date would cost less than $\$ 5$ million/year. Thus the score of $15 B$, certainty of moderate avoidable costs.

After the landfill is capped, this is reduced to 15D, the lowest score.

\section{Environmental Protection}

It is certain that ground water has been contaminated near the site boundary. At some places on-site the contamination is at high levels. This was judged to score $17 \mathrm{~A}$, a certainty of significant damage to the environment (ground water). Ground water is believed to be the only environmental media significantly impacted.

After remediation, it is judged that this risk would be reduced to $18 \mathrm{C}$, a medium risk of minor to moderate damage.

\section{Operable Unit 2}

OU-2 includes radiation-contaminated soils in several locations, and small amounts of chemically contaminated soils. It also includes the AGS storage yards and the waste concentration facility.

Only characterization work is planned for OU-2 in FY95-96. Two scenarios were scored: (1) a severe scenario that represents a reasonably severe outcome of the characterization that requires remedial action. Even in this case, however, only small areas of contamination are expected to require remediation. (2) A benign scenario that represents an outcome of the 
characterization that requires no action. The scoring for these scenarios are detailed below separately.

Operable Unit 2: Severe Scenario.

\section{Assumptions}

Characterization finds that the bulk of the affected soil contains concentrations of radionuclides (and/or hazardous chemicals) that exceed preliminary remediation goals. Removal and storage/disposal is therefore required under the Compliance Agreement. Future land use for this area is still under discussion but is tentatively slated as industrial.

\section{Inherent Worker Risk}

Contamination may extend 10 feet deep. Some soil contamination by transuranics exists near the D-tanks, but everywhere else contamination is low levels of gamma emitters. Radiation exposure to workers during soil excavation was judged to be negligible. Worker risk will be dominated by construction accidents. Risk was estimated to be marginal with medium probability ( $3 C$ ).

\section{Environmental Effects}

The area involved does not include wetlands, woodland or other environmental features. It is adjacent to buildings, parking lots, and roads. Effect was judged to be limited in area and marginal (3C).

\section{Social/Cultural/Political/Economic Impacts}

No direct effect is envisioned. Future land use for the area directly affected is industrial. Not doing the remedial action would degrade the value of land to future owners and limit future uses. There is not as much public concern over this unit as is the case for other operating units at Brookhaven, but the need to fence-off areas and create large excavations as part of the remedial action would raise public concern. (3C).

\section{Public Safety and Health}

With no action, there is a possibility of eventual formation of a groundwater plume as a result of leaching through the contaminated soil. Concentrations of contaminants, however, even if above remediation limits, are not expected to be excessive. Food-chain exposures resulting from deer grazing on the area were judged to be minimal. Without further disturbance, airborne dust should be minimal. Given a future industrial land use, risk was judged moderate (3C).

Remediation will remove the principle source of exposure resulting in a decreased risk (3D). 
Site Personnel Safety and Health

Exposure to site personnel is through joggers and walkers transversing the area. Radiation surveys have shown the exposure to be negligible (well below $20 \%$ of limits) ( $7 \mathrm{C})$.

After remediation, exposure is reduced to the minimum (7D).

\section{Compliance}

This operating unit is part of the Compliance Agreement, and failure to remediate would be non-compliance. What is known about the concentrations in soil, however indicate no significant dose to the public. Remediation goals are still being discussed. This unit was not viewed as a major ES\&H concern.

Therefore, not taking action was judged, at a high level of probability, to result in only a marginal level of noncompliance (10B).

After remediation, full compliance is expected (11D).

\section{Mission Impact}

Failure to remediate would have no direct impact on the existing research mission of Brookhaven. It would place some limits on future expansion of adjacent areas, which could result in a future minor impact. Pubic concern for this operating unit is low (13D).

After remediation, this impact would remain minimal (13D).

\section{Cost-Effective Management}

Failure to remediate the contaminated soil could lead to ground-water contamination after an extended time. If soil had to be excavated later, escalating costs of disposal would apply. Avoidable costs were estimated to be less than $\$ 5$ million per year (15B).

After cost-effective remediation, this impact would not exist (15D).

\section{Environmental Protection}

The environmental media damaged is soil. There exists a known, localized, low-level contamination of soil (18A).

After remediation, this damage is reduced to $18 \mathrm{D}$.

Operable Unit 2: Benign Scenario

\section{Assumptions}

Assume characterization finds that the bulk of the affected soil contains concentrations of radionuclides (and/or hazardous chemicals) that are below preliminary remediation goals. Remediation is then not required. Future land use for this area is still under discussion but is tentatively slated as industrial.

Inherent Worker Risk

Since there is no remediation activity, there is no worker risk (4D). 


\section{Environmental Effects}

Since there is no remediation activity, there is no environmental effect (3D).

Social/Cultural/Political/Economic Impacts

No direct effect is envisioned (4D).

Public Safety and Health

No action is required because the public health risk is low. Given a future industrial land use, risk is judged moderate (3D).

After, public health risk remains the same (3D).

Site Personnel Safety and Health

Radiation surveys have shown the exposure to be negligible (well below $20 \%$ of limits) (7D).

With no action required, the risk remains at the minimum (7D).

\section{Compliance}

Compliance, under this scenario, requires no action (11D).

With no action required, full compliance remains (11D).

\section{Mission Impact}

With no compliance necessary no impact on the existing research mission of Brookhaven is envisioned (13D).

With no action required, this impact would remain minimal (13D).

Cost-Effective Management

Cost-effective option in this scenario is no action (15D).

With no action required, this impact would not exist (15D).

\section{Environmental Protection}

The environmental media damaged is soil. There exists a known, localized, low-level contamination of soil, assumed to have a lower baseline risk in this scenario than in the severe scenario (18C).

With no action required, this damage remains at $18 \mathrm{C}$. Note that while the initial condition is lower than in the severe scenario, it remains constant in this scenario because no action is needed. The post-action situation, therefore, has a slightly higher risk than the post action situation in the severe scenario.

\section{Operable Unit 3}

Operable Unit 3 includes a wide range of potential sources of ground water contamination. The biggest problem is off site migration of VOCs to the south of the site and west of OU-1. 


\section{Inherent Worker Risk}

Risks to workers are dominated by the mechanical risk of working around heavy equipment. Marginal injuries ( $<3$ months disability) are expected with a probability of $30 \%(3 \mathrm{~B})$. Another important risk to workers is exposure to ticks and subsequent risk of Lyme disease.

\section{Environmental Effects}

There are several small areas being evaluated for residual contamination. Many of these may require removal. Minor damage to these areas will be localized and short-term (3C).

\section{Social/Cultural/Political/Economic Impacts}

A contaminated ground water plume has moved off site into a residential area partially served by domestic wells. It is unlikely that these wells are affected by the plume, but some may be. This has economic consequences on property values, causing outrage in the population, leading to social and political impact. A significant impact could develop with moderate probability $(2 \mathrm{C})$.

\section{Public Safety and Health}

Measurements on site, but near the boundary, are above drinking water standards for VOCs. The potential plume underlies a residential area in which many homes have individual domestic wells. The extent to which people are actually exposed is unknown. Further, if they are exposed, it may be from sources other than BNL. VOCs in some drinking water wells in this area have been attributed to a non-BNL industry by the Suffolk County Health Department. It is believed that any southerly plume from the BNL site may run 30-50 feet below the level at which drinking water wells are screened. Given available information, however, we estimated that there was more than a $10 \%$ chance that wells are contaminated by the laboratory (2B).

Following action being taken, pubiic exposure will be reduced substantially (3D).

Site Personnel Safety and Health

This unit has contaminated soil that may be accessible to site personnel. The risk is marginal. This unit also includes the water supply wells for the site. These are contaminated with VOC at a low level, but above drinking water standards. Carbon filtration is used to reduce the level to about $20 \%$ of drinking water standards (6C).

After action, risk will be minimal (7D).

\section{Compliance}

If no action is taken, it is certain the site will be in major non-compliance with the Compliance Agreement (8A). 
After action, compliance problems will be minimized. This was initially scored as 11D, but it was concluded at the review meeting that there is a reasonable possibility of a marginal level of noncompliance even if current plans are accomplished. A final score of $10 \mathrm{C}$ was given.

Mission Impact

No action would produce no direct affect on the Brookhaven mission. There is a high probability of indirect effects resulting from public outrage that could ultimately affect the mission (13B).

Cost-Effective Management

The action necessary as a result of characterization of the ground water plume has not yet been determined. If pump and treat were indicated, there would be savings by doing it now rather than later after the plume had further dispersed. Annual costs would be less than $\$ 5$ million (15B).

After action is taken, this is not applicable (15D).

\section{Environmental Protection}

It is certain that ground water is contaminated above drinking water standards near the site boundary and is likely to be so off site. Although perhaps above drinking water standards, the concentrations in ground water are not high. We judged this to be a virtual certainty of significant damage (17A).

If cleanup takes place, e.g., pump and treat, the level of impact could be reduced to minor (18C).

\section{Operable Unit 4}

Operable Unit 4 is in the east-central part of the site and includes the central steam facility, the Reclamation facility, Recharge Basin $\mathrm{HO}$ and leaky sewer lines.

\section{Assumptions}

A ROD will be signed during FY95. The design phase of remediation action will take place in FY96.

\section{Inherent Worker Risk}

The reclamation facility, which requires excavation of 2 to 8 feet of soil contaminated by radionuclides ( $\mathrm{Pu}, \mathrm{U}, \mathrm{Am}, \mathrm{Cs}, \mathrm{Co})$, poses a medium probability, marginal risk of exposure near limits to workers of inhalation of alpha-emitters $(3 \mathrm{C})$.

\section{Environmental Effects}

The environmental report found no critical environmental areas within OU-4. Need for excavation indicates some localized, short-term impacts may occur (3C). 


\section{Social/Cultural/Political/Economic Impacts}

No direct effect is envisioned. Future land use for the area directly affected is industrial, but a ground water plume would extend over parts of the Laboratory designated for residential use. This would degrade the value of land to future owners. Moreover, failure to take appropriate remediation action after working closely with regulators and stakeholders would destroy trust aggravating public response (3C).

\section{Stakeholder/Public Perceptions}

Not implementing planned remediation activities will result in loss of credibility with stakeholders and the public. It will open the possibility of third party legal action. Implementing planned remediation activities in a timely manner will gain stakeholder confidence and improve public perception.

\section{Public Safety and Health}

With no action, contaminated ground water will likely move beyond the area designated industrial into the area now on site but designated residential. Within this area, it may be above drinking water standards (although no measurements or modeling results are currently available to demonstrate this or to contradict it). It is not expected that ground water above drinking water standards would ever leave the site boundary from this operable unit. This area may eventually be residential with private wells. The plume would eventually move off-site, but would likely disperse to below drinking water standards by that time. The area of soil contamination may generate wind-blown dust leading to exposures in areas designated for future residential use. The probability that ground water above drinking water standards would reach the residentialdesignated area on site and that this area will be in residential use and be served by private wells is low. This was initially scored as $2 \mathrm{D}$, but in review the score was increased to $2 \mathrm{C}$. The rational for the change was that, although contaminants are expected to be less than drinking water standards if they cross the site boundary, there is at least a $10 \%$ chance they might exceed drinking water standards.

With planned remediation, only a low probability of moderate to low-level exposure remains (3D).

\section{Site Personnel Safety and Health}

Risk to site personnel is from soil contaminated with radionuclides. Windblown dust is a likely route of exposure. Joggers may be at risk. Animals, including deer, may ingest radioactive material that is transmitted through the food chain. These risks were judged to be marginal (6C).

After remediation the risk is reduced to a negligible level, but still with medium probability since not all the contaminated soil will be removed $(7 \mathrm{C})$. 


\section{Compliance}

A ROD will be signed in 1995. Failure to remediate will represent non compliance with the Compliance Agreement ( $8 \mathrm{~A})$.

Completion of remediation will still leave some small (1\%) probability of marginal noncompliance (10D).

\section{Mission Impact}

While failure to remediate would have no direct impact on the research mission of Brookhaven, public outrage resulting from no action after working carefully with regulators, other stakeholders, and the public to gain trust would, with a greater than $10 \%$ probability, overflow into political action with moderate negative impact for the overall mission of the Laboratory (13B).

After remediation, this impact would be minimal (13D).

\section{Cost-Effective Management}

Failure to act with reasonable speed to remediate the sources of groundwater contamination would lead to continued and more widespread contamination, but the extent of this contamination and the need for and cost of clean up is uncertain. (15C).

After cost-effective remediation, this impact would not exist (15D).

\section{Environmental Protection}

Both ground water and soil are contaminated above acceptable levels but over a limited area (17B).

After remedial action, levels are reduced to minor, although some residual will remain $(18 \mathrm{C})$.

\section{Operable Unit 5}

Operable Unit 5 includes the sewage treatment plant, Imhoff tank, satellite disposal area, and eastern flowing ground water plume. OU-5 only involves characterization during FY95-96. Not enough information was available to adequately characterize the risks associated with this Operable Unit. Therefore, two scenarios were scored: (1) a severe scenario that represents a severe outcome of the characterization requiring remedial action and (2) a benign scenario that represents an outcome of the characterization that requires no action. The two scenarios are detailed below separately.

\section{Operable Unit 5: Severe Scenario}

\section{Assumptions}

The severe scenario assumes the characterization detects tritium at levels above drinking water standards in off-site wells (tritium was detected in off site wells 10 years ago but has not been detected recently above drinking water 
standards). It is also assumed that high levels of VOC routinely found in a domestic drinking water well is found to represent wide-spread contamination linked to the Brookhaven site. Actions required are assumed to be: (1) provide public water to off-site community to the east; (2) remediate ground water for VOC by pump and treat; (3) remediate the satellite disposal area - assumed to be the source (chemical wastes buried here were previously retrieved, but magnetic search indicates unknown materials are still there); and (4) remove the Imhoff tank and its contents (this removal is planned in any event, but characterization will determine the size of the effort involved).

\section{Inherent Worker Risk}

Based on removal of the sludge and liquid in the Imhoff tank and related soil contamination and/or excavation and removal of waste at the satellite disposal area a $1-10 \%$ probability of a marginal risk to workers is estimated (3C).

\section{Environmental Effects}

Only small areas would require disturbance of the terrestrial ecology for excavation. This is minor damage, but would occur with high likelihood (3B).

Social/Cultural/Political/Economic Impacts

Discovery that contamination underlies off-site property would have a downward effect on property values with significant economic consequences. This would lead to significant social and political impacts. These impacts would be highly likely. Failure to take appropriate remediation action after working closely with regulators and stakeholders would destroy trust aggravating public response (2B).

\section{Public Safety and Health}

Off-site ground water plumes with concentrations above drinking water standards in domestic wells result in an excessive exposure. Under this scenario, this exposure is assumed to be a certainty (2A). This finding is supported by current concentrations of VOC above drinking water standards in an off-site well (not confirmed to be attributable to a Brookhaven source).

After remediation, the impact is reduced to a low probability of low-level exposure (3D)

Site Personnel Safety and Health after).

No reasonable route of exposure to site personnel exists (7D before and

\section{Compliance}

The Compliance Agreement specifies that appropriate remediation will follow characterization. Under this scenario, no action would be a certain violation of the Compliance Agreement (8A). 
Following remediation, a low probability $(<1 \%)$ marginal noncompliance remains due to inadequacy of existing technology to achieve required reduction in ground water concentration (10C).

\section{Mission Impact}

While failure to remediate would have no direct impact on the research mission of Brookhaven, public outrage resulting from no action after working carefully with regulators, other stakeholders, and the public to gain trust would, with up to $10 \%$ probability, overflow into political action with moderate negative impact for the overall mission of the Laboratory (13C).

After remediation, this impact would be minimal (13D).

\section{Cost-Effective Management}

Failure to act with reasonable speed to remediate the sources of groundwater contamination would, with more than $10 \%$ probability, lead to continued and more widespread contamination that would eventually cost more than $\$ 1$ million per year to control (15B).

After cost-effective remediation, this impact would not exist (15D).

\section{Environmental Protection}

This scenario assumes certain contamination of ground water off-site at levels that are above drinking water standards, but not extremely high. We judge this to be significant, but not catastrophic, environmental damage (17A).

\section{Operable Unit 5: Benign Scenario}

Inherent Worker Risk

The Imhoff tank and its contents will still be removed, so some small worker risk remains $(4 C)$.

\section{Environmental Effects}

Since no action is necessary for this scenario, there is no environmental effect (3D).

\section{Social/Cultural/Political/Economic Impacts}

The need to put test wells in a residential area and to test domestic wells will raise concerns, although the overall impact will be small (4B).

\section{Stakeholder/Public Perceptions}

Public Safety and Health

This scenario, by definition as low risk (3D). Since no action is taken, this is the same before and after.

Site Personnel Safety and Health

No reasonable route for exposure to site personnel exists (7D). Since no action is taken, this is the same before and after. 


\section{Compliance}

This scenario requires no action, thus is by definition in compliance (11D). Since no action is taken, this is the same before and after.

Mission Impact

No mission impact is envisioned (13D). Since no action is taken, this is the same before and after.

\section{Cost-Effective Management}

Not applicable since the cost effective action is no action (15D). Since no action is taken, this is the same before and after.

\section{Environmental Protection}

The scenario allows a low level of contamination (18C). Since no action is taken, this is the same before and after.

\section{FOCUS ON OFF-SITE PLUMES}

\section{Consistent Assumptions for Off-site Plumes}

Operable Units 1, 3 and 5 all had ground-water plumes that went beyond the site boundary or were likely to go off the site boundary. It was felt necessary to be sure these plumes were scored in a consistent manner, especially in categories Public Health, Compliance, and Environmental Protection. This required that there be a consistent set of assumptions on what action would be taken regarding these ground-water plumes. These assumptions were developed for the purpose of scoring only. They are guesses about what might happen. Decisions on what actually will be done must be made jointly by the parties to the Compliance Agreement. These decisions are not required yet and, in some cases, more characterization inforrnation will be required before they can be made intelligently.

For the scoring, it was assumed that if characterization verifies that plumes are moving off site at concentrations above ground water standards they will be cleaned up. It was recognized, however, that this may not happen because it may prove impracticable to do so. If they are not cleaned up, then the following assumptions would apply.

\section{Health}

If domestic wells were affected above drinking water standards, assume public water supply will be provided and public health and safety risks eliminated. 


\section{Compliance}

Assume the parties to the Compliance Agreement agree with that decision and thus BNL remains in compliance.

An alternative possibility is that, rather than agreeing not to clean up, the parties to the Compliance Agreement may require BNL to take action. In that case we assume BNL implements the required treatment and keep trying to clean up. Still in compliance.

\section{Environment}

An off site ground water plume that exceeds drinking water standards is, by definition, environmental damage.

\section{Scoring the Off site Plumes}

\section{Health}

The DOE guidance for Public Health has three levels of impact. The lowest level (3) was defined as exposure "no greater than published acceptable limits." We took this to mean below drinking water standards. The second level (Excessive exposure) was defined as "exceeding published acceptable limits." The highest level (1) of impact (Immediate or eventual loss of life) mentions future cancer deaths that might result from materials that breach the site boundaries, without mention of standards. We judged level 1 to imply a much higher level of risk than posed by the BNL off-site plumes.

We therefore ranked the off-site plumes as a level 2. The likelihood that off-site plumes are above drinking water standards was judged to be over $10 \%$, which was the criteria in the DOE guidance for a high level of likelihood (level B). This was the level applied to Operable Units 1 and 3 . Information on Operable Unit 5 was insufficient to form the basis of a score, so a severe and a benign scenario were scored. Since the Severe Scenario assumed the off-site ground-water would be above drinking water standards, a likelihood value of $A$ (certainty) was applied.

\section{Environmental Impact}

This score provided a quandary. The guidance provided the following impact levels:

Level 16 (Catastrophic damage) -- not easily containable and several years to reverse.

Level 17 (Significant damage) -- wide spread but reversible in 1 year or limited and require several years

Level 18 (Minor to moderate damage) - limited area + reversible in 1 year

The BNL ground-water plumes are fairly limited but would clearly take more than one year to mitigate. Level 17 appeared the obvious choice of score. 
The example used in the DOE guidance for level 1, however, appeared to fit the BNL case closely. It was our judgment, confirmed by the overall BNL review group, that the BNL plumes are not "catastrophic" and that a graded approach demanded scoring an environmental impact level 17, "significant."

\section{INTERNAL CONSISTENCY CHECK OF OPERABLE UNIT SCORING}

An internal check was performed to ensure consistency in the scores. Assumptions and a consistency check for issues related to off-site ground water contamination were described in the previous section.

Worker Risk

The high score $(2 \mathrm{C})$ for OU-1 was based on a possible explosion in the chemical holes. The other scores reflect risks of working with mechanical equipment more than radiation or chemical exposure.

Environmental Effects

No consistency problems were identified.

Social/Cultural/Political/Economic

The only substantial effects identified were related to off site ground water plumes. These were effects on real estate values and public fear and outrage. Consider the relative scores of OU-1 (2A), OU-3 (2C), and OU-5S (2B).

Public Health and Safety

OU- 1 and OU- 3 were scored $2 \mathrm{~B}$. OU- 5 is $2 \mathrm{~A}$ only because it is a severe scenario, thus we assume a level 2 is certain, while in OU-1 and OU-3 there is only a high probability. The original score for $\mathrm{OU}-4$ was $2 \mathrm{~B}$. Relative to these, 2B for OU-4 seems too high a probability.

Site Personnel Safety and Health

No inconsistencies noted.

Compliance

No inconsistencies noted.

Mission Impact

No inconsistencies noted.

Cost Effective Mar!agement

Failure to take timely action at the source of the major ground water plumes may not be cost effective, so Operable Units 1,3 and $5 S$ are scored $15 \mathrm{~B}$. By comparison, we recommend $\mathrm{OU}-2 \mathrm{~S}$ and $\mathrm{OU}-4$ be downgraded to $15 \mathrm{~B}$ and $15 \mathrm{C}$ respectively from $15 \mathrm{~A}$. 


\section{Environmental Protection}

We do not believe the label "Catastrophic Damage" applies to the BNL off site plumes (even if they are found to be contaminating domestic wells). The concentration levels that can be expected do not represent the "most severe environmental effects." On the other hand, the example given by DOE (p. 16; in Appendix 1) seems to fit our situation. The example does not seem to differentiate between a plume slightly over the drinking water standards and one that greatly exceeds standards.

After reviewing the scores and considering the matter in the light of the more graded approach used in other categories, our recommendation is that OU-1, OU-3, and OU-5 be scored 17A "before", that is "serious" rather than "catastrophic." OU-4, by comparison, should be 17B. Original scores were: OU3 16A; OU-4: 17A and OU-5S: 16A.

\section{SECOND ROUND SCORING}

After the risk scoring was completed, DOE Chicago Operations Office requested that Program Management and "Site Wide Activities" be scored. The risk prioritization and scoring model was appropriate for neither of these activities. In both cases it was necessary to develop a rationale for the scoring. In addition, the original scoring assumed that the Spray Aeration Removal Action was including in Operations Unit I. DOE requested this Removal Action be rescored as part of a Removal Action that previously was based on the risk of cesspools (ADS 2310). This scoring is detailed in Appendix 4.

\section{Site-Wide Activities}

Site-wide activities include a variety of characterization tasks that support all Operable Units. This includes characterization of the overall hydrogeologic system for the BNL site and surrounding area. The relative contribution of sidewide activities may vary among Operable Units, but it was difficult to apportion the impact of information developed site-wide among the Operable Units. As a general support activity for all Operable Units, it was decided that the "before" scores were taken as the highest score among all the Operable Units for each category before cleanup and the "after" were taken as the highest score among all the Operable Units for each category after cleanup.

\section{Program Management}

Program management is the overall management function controlling the BNL OER. It is a separate activity for budgeting purposes, but poses no direct risks through its own activity. The scoring model was not especially appropriate for evaluation of program management. Program management, of course, can affect the level of risk associated with the work done in each of the operable 
units. It is responsible for management control, training, quality control, community involvement, and oversight, without which all operations in OER might be carried out less carefully (not all the Project Engineers agreed with this). Some thought was given to scoring Program Management as "with" and "without." It was noted that Program Management was responsible for submitting budget proposals to DOE. If these were not submitted, there would be no funding and thus no mitigation of risk. The DOE guidelines, however, specify that the scoring be based on "before" and "after." Since Program Management was responsible for the entire OER activity, it was then responsible for all risks associated with those activities. The general guideline developed above for the Operable Units was that the element in the operable unit that had the highest risk would be the basis for the "before" score and that the element with the highest risk after cleanup would be the basis for the "after" score. Applying the same approach to overall Program Management, the "before" scores were taken as the highest score among all the Operable Units for each category before cleanup and the "after" were taken as the highest score among all the Operable Units for each category after cleanup.

\section{DOE INTERPRETATION}

DOE reviewed the risk scores as submitted by BNL and other facilities and converted each score into a high-medium-low scale. These results, taken from the DOE draft report, Risks and the Risk Debate: Searching for Common Ground, the First Step, Volume III, Appendix C, June 1995, are shown in Table 4.

\section{CONCLUSIONS AND RECOMMENDATIONS}

Specific comments on the risk scoring process were transmitted to the Brookhaven Area Office (Appendix 3). Major issues that affect the technical basis of the scoring are summarized below.

\section{Qualitative vs. Quantitative Analysis}

The matrix is advertised as a qualitative risk-based approach, but it is clearly being converted to a quantitative scoring process (like the EH RiskBased Priority Model). It is inappropriate to describe such large and complex activities by a single score, and the rankings by category should accompany each package.

EM needs to use risk assessment as an integral part of risk management for the DOE complex, but the scoring process implemented here should be considered a tool and not the only factor used in risk management decisions. The ranking system is subjective and may be more useful for internal ranking of 
activities at a specific site than for determining relative priority between activities at different sites.

\section{Public Health and Safety}

The definitions of public health and safety impacts given in the scoring guidance require clarification. The rankings as they appear in the current guidance appear to assume thresholds below which exposure to radiation and chemical carcinogens pose no health risk. Impacts 2 and $\mathbf{3}$ are reasonably consistent with each other: Impact 2 is excessive exposure above acceptable limits; Impact 3 is exposure less than acceptable limits with no detectable increase in cancer incidence. The only problem with these definitions is the definition of "detectable "increase -- concentrations slightly (or even significantly) above acceptable limits are not likely to produce a detectable increase in cancer incidence. We suggest removing the reference to a detectable increase in cancer incidence. The problem comes with the definition of Impact 1: it combines "immediate deaths and disabling injuries" with "future cancer deaths of genetic damage", and, if taken literally, suggests that any potential off-site exposure be ranked as Impact level 1. We suggest that Impact level 1 be restricted to risks that truly have catastrophic potential.

\section{Environmental Protection}

The description of the rankings for environmental protection require clarification. Catastrophic damage to the environment (Impact 16) includes effects spread over a wide area that are irreversible or require several years to reverse. The example suggests that ground water contamination above drinking water standards be termed Impact 16 (catastrophic damage). The definitions and example do not seem to differentiate between a dilute plume, most of which is below or only slightly above drinking water standards, and one that greatly exceeds standards and is likely to significantly degrade the resource for many years into the future. We suggest a more graded approach, similar to the one used for public health impacts: catastrophic damage to the resource, excessive contamination of the resource above standards, and moderate to low-level contamination of the resource. 


\begin{tabular}{|c|c|c|c|c|}
\hline $200^{\circ} 0$ & 20 & $\tau$ & $0 \tau$ & 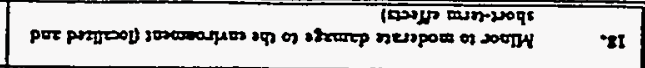 \\
\hline $20^{\circ} 0$ & $z$ & $0 z$ & 002 & 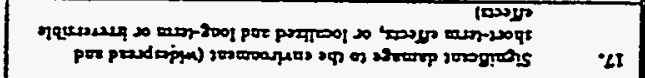 \\
\hline \multirow[t]{2}{*}{20} & \multirow[t]{2}{*}{02} & \multirow[t]{2}{*}{002} & \multirow[t]{2}{*}{0002} & 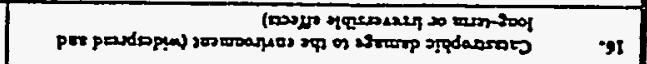 \\
\hline & & & & 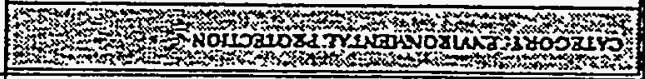 \\
\hline $5100^{\circ} 0$ & $S T^{\circ} \mathrm{O}$ & $5 I$ & SI & 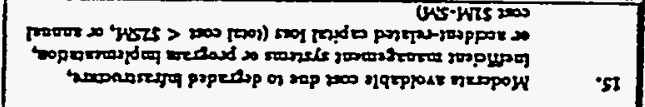 \\
\hline \multirow[t]{2}{*}{$+\infty 0^{\circ} 0$} & \multirow[t]{2}{*}{80} & \multirow[t]{2}{*}{1} & \multirow[t]{2}{*}{ ot } & 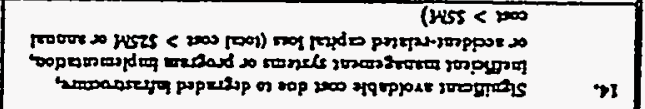 \\
\hline & & & & SW \\
\hline$S \angle 00^{\circ} 0$ & $S L^{\circ} O$ & $S L$ & SL & 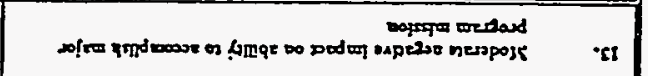 \\
\hline \multirow[t]{2}{*}{ Sto'0 } & \multirow[t]{2}{*}{$\overline{S I}$} & \multirow[t]{2}{*}{$\boldsymbol{I}$} & \multirow[t]{2}{*}{$.05 I$} & 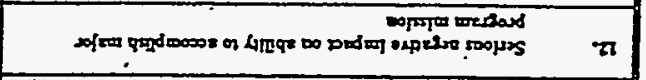 \\
\hline & & & & (W) \\
\hline
\end{tabular}

\begin{tabular}{|c|c|c|c|c|}
\hline $1000^{\circ} 0$ & $10 \%$ & I.0 & $I$ & 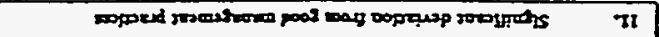 \\
\hline $200^{\circ} 0$ & $\tau 0$ & $\mathbf{z}$ & 02 & 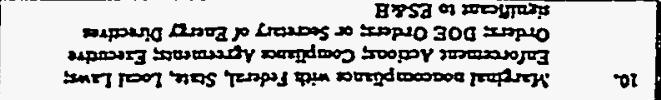 \\
\hline$S \angle O O^{\circ} O$ & SLO & $S L$ & SL & 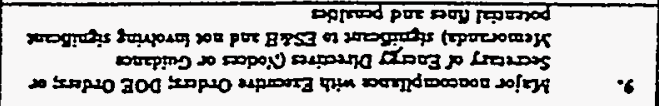 \\
\hline \multirow[t]{2}{*}{$\mathbf{S I 0} 0$} & \multirow[t]{2}{*}{$5 I$} & \multirow[t]{2}{*}{ SI } & \multirow[t]{2}{*}{ OSI } & 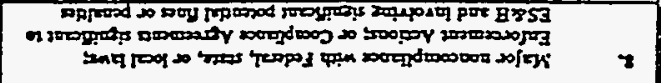 \\
\hline & & & & 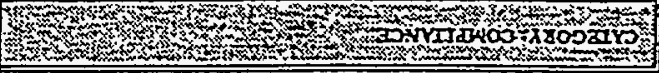 \\
\hline $100^{\circ} 0$ & I*0 & $\mathbf{I}$ & or & 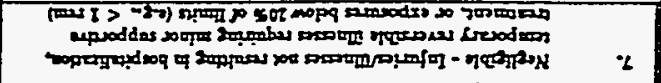 \\
\hline $10^{\circ} 0$ & I & OI & OOI & 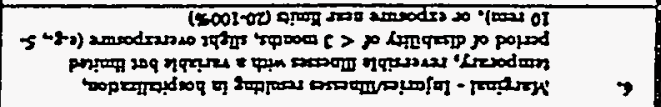 \\
\hline $20^{\circ} 0$ & $\tau$ & $0 Z$ & 002 & 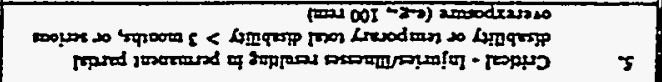 \\
\hline \multirow[t]{2}{*}{20} & \multirow[t]{2}{*}{$0 z$} & \multirow[t]{2}{*}{002} & \multirow[t]{2}{*}{0002} & 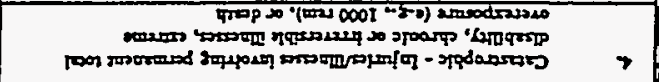 \\
\hline & & & & 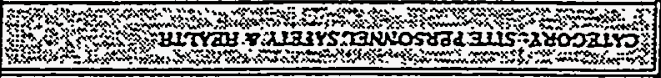 \\
\hline $800^{\circ} 0$ & $\Sigma 0$ & $\boldsymbol{\varepsilon}$ & or & mosodes pespmol ol serpous \\
\hline $\mathrm{EO}^{\circ} \mathrm{O}$ & $\boldsymbol{\varepsilon}$ & $O \varepsilon$ & OOE & 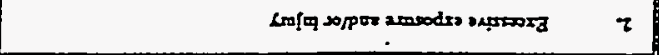 \\
\hline \multirow[t]{2}{*}{ EO } & \multirow[t]{2}{*}{ or } & \multirow[t]{2}{*}{$00 \varepsilon$} & \multirow[t]{2}{*}{ OOOE } & 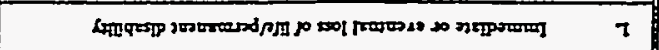 \\
\hline & & & & ond \\
\hline $\operatorname{son}$ & 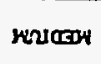 & BOR & $\begin{array}{l}\text { RODH } \\
\text { Xran }\end{array}$ & SIDYdWU \\
\hline $\mathbf{a}$ & 5 & $\mathbf{8}$ & $\overline{\mathbf{V}}$ & \\
\hline
\end{tabular}

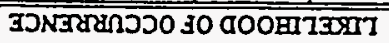

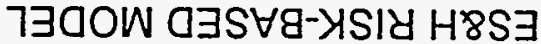

$\llcorner\exists 7 g \forall \perp$ 
TABLE 2. SUMMARY OF SCORES BY OPERABLE UNIT.

Scores given for OU-2 and OU-5 are for the "severe scenario".

\begin{tabular}{|c|c|c|c|c|c|}
\hline Category & $O U-1$ & $0 U-2 \mathrm{~S}$ & OU-3 & OU-4 & OU-5 S \\
\hline $\begin{array}{l}\text { Worker risk } \quad 1=\text { Catastrophic } 2=\text { Critical } \\
3=\text { Marginal } 4=\text { Negligible }\end{array}$ & $1 \mathrm{C}$ & $3 C$ & $3 B$ & $3 C$ & $3 C$ \\
\hline $\begin{array}{l}\text { Environmental Effects } 1=\text { Catastrophic } 2=\text { Significant } \\
3=\text { Minor }\end{array}$ & $2 B$ & $3 c$ & $3 c$ & $3 C$ & 38 \\
\hline $\begin{array}{l}\text { Social, etc Effects } 1=\text { Catastrophic } 2=\text { Significant } \\
3=\text { Moderate } 4=\text { Minor }\end{array}$ & $2 \mathrm{~A}$ & $3 C$ & $2 C$ & $3 c$ & $2 B$ \\
\hline $\begin{array}{l}\text { Public Health and Safety } 1=\text { loss of life; } 2= \\
\text { Excessive exposure; } 3=\text { Low level exposure }\end{array}$ & $2 B / 3 D$ & $3 C / 3 D$ & $2 B / 3 D$ & $2 C / 3 D$ & $2 A / 3 D$ \\
\hline $\begin{array}{l}\text { Site Personnel S\&H } 4=\text { Catastrophic; } 5=\text { Critical; } \\
6=\text { Marginal; } 7=\text { Negligible }\end{array}$ & $70 / 70$ & $7 C / 7 D$ & $60 ; 70$ & $6 c / 7 c$ & $70 / 70$ \\
\hline $\begin{array}{l}\text { Compliance } 8=\text { Major w/haw or compliance } \\
\text { agreement; } 9=\text { Major w/ DOE orders: } 10=\text { Marginal } \\
\text { noncompliance; } 11=\text { Deviation from good practice }\end{array}$ & $8 \mathrm{~A} / 10 \mathrm{C}$ & $10 \mathrm{~B} / 11 \mathrm{D}$ & $8 \mathrm{~A} / 10 \mathrm{C}$ & $8 A / 10 D$ & $8 \mathrm{~A} / 10 \mathrm{C}$ \\
\hline $\begin{array}{l}\text { Mission Impact } 12=\text { Serious impact: } 13=\text { Moderate } \\
\text { impact }\end{array}$ & $13 C / 13 D$ & $13 D / 13 D$ & $13 B / 13 D$ & $13 B / 13 D$ & $13 C / 13 D$ \\
\hline $\begin{array}{l}\text { Cost-effective Managemt } 14=\text { Avoidiable costs } \\
>5 \$ \mathrm{M} / \mathrm{y} \quad 15=\text { Avoidable costs }<\$ 5 \mathrm{M} / \mathrm{y}\end{array}$ & $15 B$ & $15 B$ & 158 & $15 \mathrm{C}$ & $15 B$ \\
\hline $\begin{array}{l}\text { Environmental Protection } 16=\text { Catastrophic damage } \\
17=\text { Significant damage } 18=\text { Minor damage }\end{array}$ & $17 \mathrm{~A} / 18 \mathrm{C}$ & $18 \mathrm{~A} / 18 \mathrm{D}$ & $17 A / 18 C$ & $17 B / 18 C$ & $17 A / 18 C$ \\
\hline
\end{tabular}


TABLE 3. SUMMARY OF "BENIGN" AND "SEVERE" SCORES FOR OU-2 AND OU-5.

\begin{tabular}{|c|c|c|c|c|}
\hline Category & $0 U-2 S$ & $O U-2 B$ & OU-5 S & OU-5 B \\
\hline $\begin{array}{l}\text { Worker risk } \quad 1=\text { Catastrophic } 2=\text { Critical } \\
3=\text { Marginal } 4=\text { Negligible }\end{array}$ & $3 C$ & $4 D$ & $3 C$ & $4 C$ \\
\hline $\begin{array}{l}\text { Environmental Effects } 1=\text { Catastrophic } 2=\text { Significant } \\
3=\text { Minor }\end{array}$ & $3 C$ & $3 D$ & $3 B$ & $3 D$ \\
\hline $\begin{array}{l}\text { Social, etc Effects } 1=\text { Catastrophic } 2=\text { Significant } \\
3=\text { Moderate } 4=\text { Minor }\end{array}$ & $3 C$ & $4 D$ & $2 B$ & $4 B$ \\
\hline $\begin{array}{l}\text { Public Health and Safety } 1=\text { loss of life; } 2= \\
\text { Excessive exposure; } 3=\text { Low level exposure }\end{array}$ & $3 C / 30$ & $30 / 30$ & $2 A / 3 D$ & $3 D / 3 D$ \\
\hline $\begin{array}{l}\text { Site Personnel S\&H } 4=\text { Catastrophic; } 5=\text { Critical; } \\
5=\text { Marginal; } \quad 7=\text { Negligible }\end{array}$ & $70 / 70$ & $70 / 70$ & $70 / 70$ & $7 D / 7 D$ \\
\hline $\begin{array}{l}\text { Compliance } 8=\text { Major w/law or compliance } \\
\text { agreement; } 9=\text { Major w/ DOE orders; } 10=\text { Marginal } \\
\text { inoncompliance; } 11=\text { Deviation from good pracii } 8\end{array}$ & $10 \mathrm{~B} / 11 \mathrm{D}$ & $110 / 110$ & $8 \mathrm{~A} / 10 \mathrm{C}$ & $110 / 110$ \\
\hline $\begin{array}{l}\text { Mission Impact } 12=\text { Serious impact; } 13=\text { Moderate } \\
\text { impact }\end{array}$ & $13 D / 13 D$ & $130 / 130$ & $13 C / 13 D$ & $130 / 130$ \\
\hline $\begin{array}{l}\text { Cost-effective Managemt } 14=\text { Avoidable costs } \\
>5 \$ \mathrm{M} / \mathrm{y} \quad 15=\text { Avoidable costs }<\$ 5 \mathrm{M} / \mathrm{y}\end{array}$ & $15 B$ & 15D & 758 & $15 \mathrm{D}$ \\
\hline $\begin{array}{l}\text { Environmental Protection } 16=\text { Catastrophic damage } \\
17=\text { Significant damage } 18=\text { Minor damage }\end{array}$ & $18 \mathrm{~A} / 18 \mathrm{D}$ & $18 C / 18 C$ & $17 A / 18 C$ & $18 \mathrm{C} / 18 \mathrm{C}$ \\
\hline
\end{tabular}


TABLE 4. DOE INTERPRETATION OF RISK SCORES

\begin{tabular}{|l|l|l|l|l|l|l|l|l|l|}
\hline Operable Unit & \multicolumn{5}{|c|}{ Before and After Risk Levels } & Work & Env & Soc \\
\hline & Pub & Site & Compl & Mis'n & CstE & $\begin{array}{l}\text { Env } \\
r\end{array}$ & & & \\
\hline 1 & M/L & L/L & H/L & M/L & M/M & H/L & M & M & H \\
\hline 2-severe & L/L & L/L & M/L & L/L & M/M & M/M & L & L & L \\
\hline 3 & M/L & L/L & H/L & M/L & M/M & H/L & M & L & M \\
\hline 4 & M/L & L/L & H/L & M/L & M/M & M/L & L & L & L \\
\hline 5-severe & H/L & L/L & H/L & M/L & M/M & H/L & L & M & M \\
\hline 2- benign & L/L & L/L & L/L & L/L & L/L & LL & L & L & L \\
\hline 5-benign & L/L & L/L & L/L & L/L & L/L & L/L & L & L & L \\
\hline RA-3 & L/L & L/L & M/L & M/M & M/L & M/M & L & L & L \\
\hline Sitewide & H/L & L/L & M/L & M/L & M/L & H/L & L & L & L \\
\hline
\end{tabular}




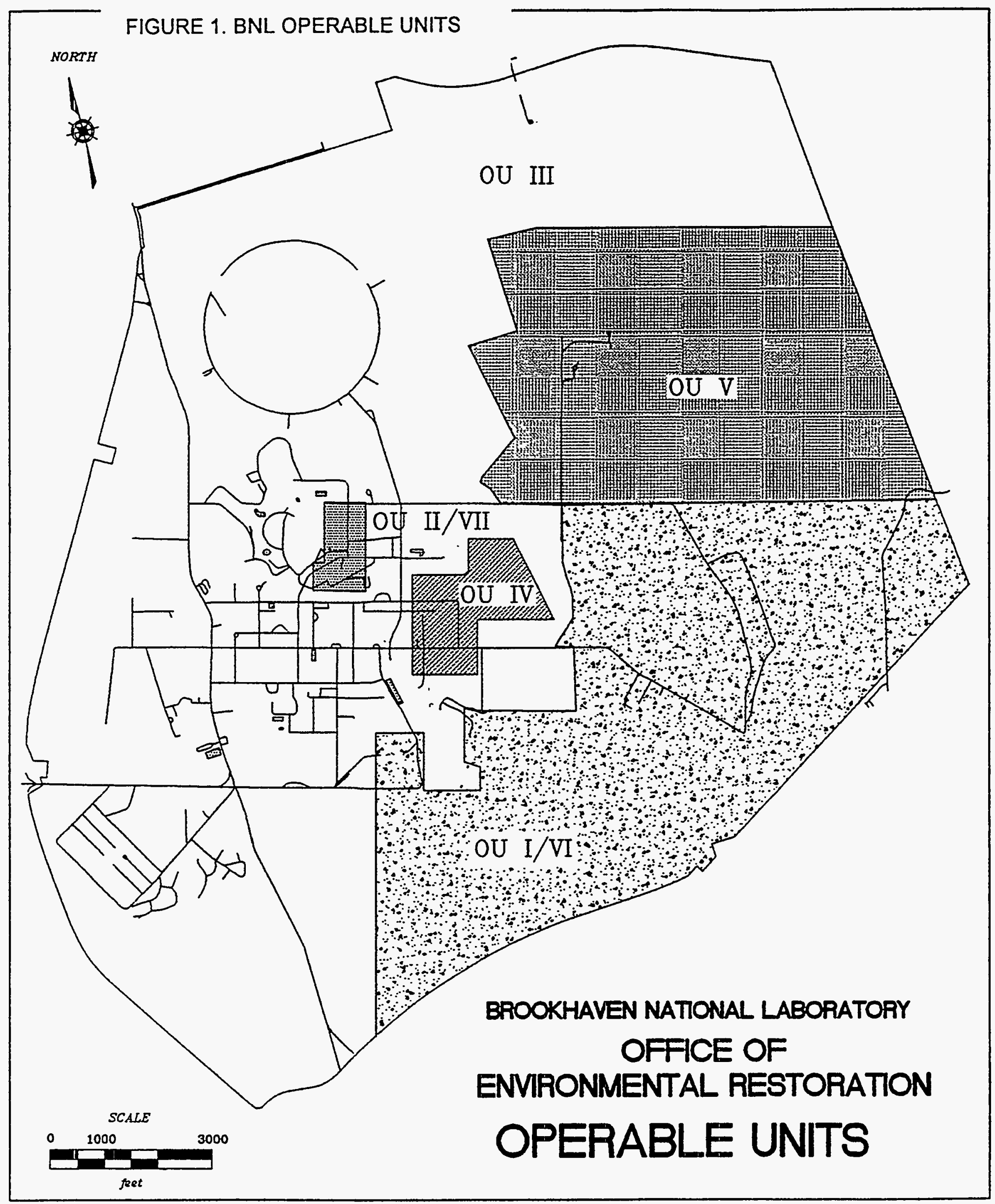




\section{APPENDIX 1 DOE GUIDELINES}

Extensive guidelines on the risk prioritization were provided under a letter from J. O. Neff of DOE Chicago Operations dated February 27, 1995. One set of scoring categories was based on a risk scoring approach developed by DOE$\mathrm{EH}$. The categories were described as follows:

"Public Safety and Health includes potential adverse impacts on the health and safety of the off-site population surrounding a facility".

"Site Personnel Safety and Health includes potential adverse impacts on the safety and health of individuals inside the facility boundary. This includes site workers and visitors".

"Compliance includes failures to comply with laws, regulations, compliance agreements, Executive Orders, and DOE Orders that govern EM facility operations and projects. Such failures may adversely affect the confidence of DOE or other agencies in the ability of the facility to operate while protecting the public, workers, and the environment".

"Mission Impact includes potential adverse impacts on the ability to perform a mission of a DOE facility or the ability to carry out important parts of the mission".

"Cost Effective Risk Management includes potential accidental losses to a facility's capital investment (building, equipment) or failures to take advantage of existing opportunities for cost savings, such as infrastructure upgrades, management systems upgrades, or improved program development. Such opportunities should involve investments that save resources over the life of a project or activity because problems are resolved before conditions cieteriorate further (e.g., remediation of a site is accomplished before contamination spreads further, requiring more costly work)."

"Environmental Protection includes potential adverse harmful impact on natural resources or the ecology (air, water, land, wildlife)."

The scoring form and the weights given to each category and likelihood are shown in Table 1. Examples were provided for each category. Each Operable Unit was to be scored for the risk before and after clean-up. The scores from this table formed a Qualitative Risk Matrix (QRM).

The second set of scoring categories followed the same format. Guidelines specified that these categories would not be considered when applying the Qualitative Risk Matrix (QRM). These categories include

"Inherent Worker Risk - This is an attempt to capture the actual or potential risk inherent to the worker during the implementation of the RDS [Risk Data Sheet] activities." impact levels were: 
1. Catastrophic - Injuries/illnesses involving permanent total disability, chronic or irreversible illnesses, extreme overexposure, or death.

2. Critical - Injuries/illnesses involving permanent partial disability or temporary total disability $>3$ months, or serious overexposure.

3. Marginal - Injuries/illnesses resulting in hospitalization, temporary, reversible illnesses with a variable but limited period of disability of $<3$ months, slight overexposure or exposure near limits $(20-100 \%)$.

4. Negligible - Injuries/illnesses not resulting in hospitalization, temporary reversible illnesses requiring minor supportive treatment or exposures below $20 \%$ of limits.

"Environmental Effects - This is an attempt to capture the actual or potential impact to the environment during the implementation of the RDS activities." Impact levels were:

1. Catastrophic damage to the environment (widespread and long-term or irreversible effects).

2. Significant damage to the environment (widespread and shortterm effects, or localized and long-term or irreversible effects).

3. Minor to moderate damage to the environment (localized and short-term effects).

"Social/Cultural/Political/Economic Impact - This is an attempt to broadly capture the risk to social, cultural, political, and economic values (e.g., desire of Tribal Nations) of completing and/or not completing the activity." Impact levels were:

1. Catastrophic damage to the social, cultural, political, or economic conditions of the local area affected by completing or not completing the activity.

2. Significant damage to the social, cultural, political, or economic conditions of the local area affected by completing or not completing the activity.

3. Moderate damage to the social, cultural, political, or economic conditions of the local area affected by completing or not completing the activity.

4. Minor damage to the social, cultural, political, or economic conditions of the local area affected by completing or not completing the activity.

Likelihood levels associated with these categories were: 
Very High - 1.0 per year: representing impacts that already exist or occur at least once per year.

High - $\quad 0.1$ per year: representing impacts expected to occur at least once per ten years but less than once per year.

Medium - $\quad 0.01$ per year: representing impacts expected to occur at least once per 100 years but less than once per ten years.

Low - $\quad 0.0001$ per year: representing impacts expected to occur at least once in 10,000 years, but less than once per 100 years. 
APPENDIX 2 SITE SPECIFIC ASSUMPTIONS 
Dr. Carson L. Nealy, Manager

Brookhaven Area Office

U.S. Department of Energy

Upton, NY 11973

Dear Dr. Nealy:

Subject: Environmental Management Risk Prioritization Evaluation

Attached is the Brookhaven National Laboratory Site Specific Assumptions that are used in the Environmental Management Risk Prioritization Evaluation. A copy has been faxed to Dr. Kelly Tzoumis. BNL would like an opportunity, sometime in the future, to comment on this process.

Please contact me if you have any questions.

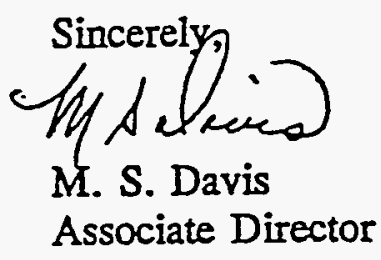

kr

Attachment: BNL Environmental Management Risk Prioritization Assumptions

c: $\quad$ M. H. Brooks

W. R. Casey

D. W. Dains

L. C. Emma

W. E. Gunther

A. Harvey

A. F. Meinhold

S. C. Morris

C. Polanish

$\mathrm{K}$. Tzoumis 


\section{Brookhaven National Laboratory \\ Upton, New York \\ Environmental Management Risk Prioritization Assumptions \\ March, 1995}

\section{Mission Objectives}

Brookhaven National Laboratory has as a major core competency--the ability to design, build and operate leading edge user research facilities. Nationally, there will be a continuing need for such large complex facilities in a variety of fields of science and technology available for use by the entire scientific community including the universities, other government agencies and industries. BNL therefore intends to use this expertise to operate and continuously improve existing facilities, to maintain state-of-the-art capability and to create the next generation user facilities of even greater power and utility.

Together with these facilities, BNL will continue to maintain the essential world class research efforts that are needed to drive the performance of the facilities and other research activities that greatly profit from a rich mix of research tools in close proximity. The Laboratory will continue to play a major role in providing the underlying science and technology for the DOE missions in basic and applied research, energy and environmental sciences, material science and biotechnology sciences.

Environment, safety and health will play an increasing role in society and in the overall operations of the Laboratory. This will result in stronger support for the development of technologies that reduce, rectify and/or eliminate problems. It will also lead to stronger and proactive inclusion of ESH principals in our operations.

\section{Future Land Use}

The Laboratory is actively involved with the local stakeholders in the development of a Future Land Use Plan. The basic time frames of interest to the local stakeholder are the period of time during which BNL will continue to operate as a National Laboratory and expand it's capabilities and that period of time following the cessation of BNL as a National Laboratory. The assumptions for the continued operation of BNL include:

- Expansion of and improvements to the existing research facilities.

- Development of new user facility capabilities, including a proton radiation therapy facility, a free electron laser users facility and a muon collider.

- Improvements to the infrastructure of the site; e.g., sewage system, potable water system, electrical distribution system and general building improvement for fire protection and life safety.

- Renovation, dismantlement or safe shutdown of older facilities depending on their condition and the cost effectiveness of renovation versus replacement. 
BNL Environmental Management Risk Prioritization Assumptions

- The Laboratory land will be zoned as industrial, parkland or residential, and all future development of the land will be guided by zoning definitions.

- Specific areas on site, not currently slated or identified with a footprint for future development, will be set aside as an ecology park area where research efforts may be conducted both by BNL scientists and those from other research communities. The land will be rezoned if operational needs require development.

- All operations of the Laboratory will continue to be conducted in a manner that assure compliance with environmental, safety and health requirements.

- All currently identified environmental restoration activities will be completed during the BNL operations period. These activities will be conducted in a manner that does not compromise current operation and with the goal of assuring that future expansion, as necessary, is viable, while assuring that future land use by other parties is not precluded.

For post BNL operations, the most likely scenarios for land use are:

- Use of the core, developed area of the site for another industry or university/educational activity.

- Use of the Peconic River Corridor and associated land on the southeast for park and recreational areas.

- Use of the remaining acreage will be for residential, parkland or industrial development.

\section{Institutional Control}

The Laboratory and DOE, or their successor, will maintain complete or partial institutional control of the site until such time that facilities are shutdown and appropriately cleaned up for use by other industrial or private concerns. Certain facilities and areas such as the research reactors at the site may require institutional control beyond that required for the remainder of the site.

\section{Environmental Restoration and Waste Management Program Assumptions}

Activities in the environmental restoration and waste management and facility transition arenas are intimately connected with the future vision of Brookbaven as a National 


\section{E BNL Environmental Management Risk Prioritization Assumptions}

Laboratory. The long-range goal for remediation, in conjunction with vigorous monitoring of BNL's continuing operations, is to restore the site environment to conditions consistent with anticipated future land uses by the year 2018 , to maintain strong environmental controls over existing operations and to assure appropriate controls over new operations. The Laboratory will continue to manage its waste in a fashion consistent with existing requirements and minimize the generation of waste. By the year 1997, the Laboratory will relocate its hazairdous and radioactive waste handling actives to new facilities that incorporate state-of-the-art barriers for environmental protection and worker health and safety. Careful management of wastes and remediation of site contamination will result in an environmentally safe site that will continue to be used to conduct world class research and that will assure the site remains a resource to the community in the post-BNL future.

Specific assumptions that relate to the risk prioritization of the site restoration activities include:

- All phases of the restoration work will be conducted in compliance with the Interagency Agreement between DOE/EPA/NY State Department of Environmental Conservation and all applicable and relevant requirements.

- All remedial activities will be conducted in compliance with BNL and other regulatory requirements for health, safety and environmental protection.

- There are no identified tribal concerns related to the site that would impact conducting remedial actives.

- Clean-up standards agreed to with the appropriate agencies will take into account the proposed zoning of the Laboratory and the projected future uses, both during BNL operations and in the post-BNL operations period.

- The Laboratory does have cultural significance as the site of World War I and II Army activities, Conservation Core activities and as the site of one of the first national laboratories dedicated to peaceful use of atomic energy.

- The major stakeholder concern is contamination of the drinking water. Offsite contamination may require the installation of public water for residents along the southern area of the site.

- The primary risk to the public that is addressed by the restoration program is contamination of the drinking water aquifer as a result of past practices at the site. Contamination is known to exist on site and has been detected in several off-site wells. 
(BNL Environmental Management Risk Prioritization Assumptions

- The more recent landfill area will be capped in FY 1995. The aquifer restoration operation will be upgraded and reinitiated in FY 1996.

Investigation of the older landfill area, including the "glass holes, " will be completed in FY 1995 and interim risk reduction activities will be executed in FY 1996.

- The second area of concern is near the eastern boundary of the site where the Sewage Treatment Plant operations are conducted and where past research programs such as the Upland Recharge and Meadow Marsh experiments were conducted. Remedial investigation of the areas will be concluded in FY 1995. It is assumed that if remediation of part of the area is required, the most likely candidates for remedial action are the Imhoff Tanks and Sand Filter Beds at the Sewage Treatment Plant area. Groundwater treatment remediation is a possibility.

- The third area is the core area of the site where past spills and practices that are no longer considered environmentally safe may have resulted in contaminants in the ground water. Investigation of the core areas of the site will conclude in FY 1998. The most likely remedial activities include installation of filters on the potable wells and containment/treatment systems for contamination that may be going off site.

- BNL will continue operations as a premier research facility beyond the time required for site remediation.

- Closure of the site would result in a major economic impact to the region and loss of a national resource.

- Laboratory lands will be designated as industrial, residential or parkland, consistent with the proposed programs of the Laboratory and the proposed land use for the post BNL period.

Assumptions specific to Waste Management Operations include:

- There are potential environmental threats that could arise from the mismanagement of waste or accidental spills and releases. BNL has policies, procedures and response plans in place to mitigate the effects of such a release. 
- BNL will continue to manage low-level radioactive, hazardous and mixed wastes that are generated by site operations in accordance with existing requirements and permits.

- No hazardous or radioactive waste will be disposed of by land disposal at the site with the exception of those that may be agreed to with EPA and the NY State as appropriate for incorporation in the capping activities of the landfill areas.

- BNL will continue to undertake activities that minimize the amounts of radioactive, hazardous and mixed waste that are generated by site operations.

- BNL will have an approved FFCA plan that will be implemented by October, 1995.

- BNL will complete construction of the new waste management facilities and complete relocation of its operations by FY 1997.

- All radioactive and mixed waste will continue to be sent to the Hanford site for management/disposal. All hazardous waste will be sent to licensed commercial disposal facilities.

- In FY 1997-99, there will be minimal shipment and disposal of radioactive wastes. BNL will have to store significant amounts of rad-waste until the year 2000.

- $\quad$ Spent fuel from the High Flux Beam Reactor and the Brookhaven Medical Research Reactor will continue to be stored in the existing spent fuel pool until such time as space is available at other DOE facilities and shipping is commenced again, or until the Laboratory is funded for and constructs expanded storage capability. A decision of no action will result in shutdown of the HFBR within five years.

- BNL will continue to work with the Town of Brookhaven to manage sanitary/ non-hazardous waste material and to actively recycle materials.

- $\quad$ BNL will complete upgrades to its sewage system to assure minimal impact on the surrounding environment from release to the system. 
घNL Environmental Management Risk Prioritization Assumptions

Assumptions specific to facility transition activities:

- With the exception of those facilities and parts of facilities currently identified for transitioning, BNL will continue to maintain, upgrade and expand its existing physical plant. The Landlord responsibilities will remain with the DOE-ER program. Major program facility expansion will be the responsibility of the appropriate program office within DOE.

- Where possible, the appropriate responsible program office will be identified and held responsible for the initial phase of facility transitioning, i.e., interim decontamination and waste management, as required. The DOE EM facility transition program will be responsible for longer term surveillance and maintenance until the facility is ready for and funding is available for decommissioning/dismantlement.

- The Brookhaven Graphite Research Reactor has been in safe storage since 1967. This facility will undergo final decontamination and decommissioning in the next 20 years. 
APPENDIX 3 COMMENTS ON THE RISK SCORING PROCESS 
ASSOCIATED UNIVERSITIES. INC.

Office of the Director
P.O. Box 5000

Upton. New York 11973-5000

TEL (516) 282- 3711

FAX (516) 282-

E-MAIL

March 21, 1995

Dr. Carson L. Nealy, Manager

Brookhaven Area Office

U.S. Department of Energy

Upton, NY 11973

Dear Dr. Nealy:

Subject: $\quad$ Risk Data Sheets for EM-30 and EM-40

Enclosed are the hard copies and diskettes (2) of the BNL EM-30/40 Risk Data Sheets. DOE-CH is entering the EM-60 Risk Data information. We also would like to make the following comments:

Specific Comments:

- In the database, Associated Universities is incorrectly noted as ASU. It should be AUI.

- The fields 25 and 27 are not applicable to Waste Management.

- The matrix is advertised as a QUALITATIVE risk-based approach, but it is clearly being converted to a quantitative scoring process (like the EH RiskBased Priority Model). We hope (and strongly suggest) that the rankings by category are being preserved and will accompany each package, rather than simply describing the activity by a single score.

- When entering the rankings (e.g., 1, 2,3) and the probabilities $(A, B, C)$ into the database, the software automatically enters the associated weightings (e.g., $3000,300,30$ ). The original input does not appear. It would greatly facilitate proofing the final RDS is the original rankings were printed.

- The distinction between the appraisal section and the assessment comments needs clarification. It would seem that the assessment comments could easily be incorporated into the appraisal section, simplifying the form. 
- For projects for which characterization is not complete, the guidance suggests performing two sets of assessments, but gives no guidance on how to treat these two sets of scores for a single RDS in the database.

- The definitions of public health and safety impacts require clarification. The rankings as they appear in the current guidance appear to assume thresholds below which exposure to radiation and chemical carcinogens pose no health risk. Impacts 2 and 3 are reasonably consistent with each other: Impact 2 is excessive exposure above acceptable limits and Impact 3 is exposure less than acceptable limits with no detectable increase in cancer incidence. The only problem with these definitions is the definition of "detectable" increase-concentrations slightly (or even significantly) above acceptable limits are not likely to produce a detectable increase in cancer evidence. We suggest removing the reference to a detectable increase in cancer incidence. The problem comes with the definition of Impact 1: it combines "immediate deaths and disabling injuries" with "future cancer deaths of genetic damage," and, if taken literally, suggests that any potential offsite exposure be ranked as Impact Level 1 . We suggest that Impact Level 1 be restricted to risks that truly have catastrophic potential.

- The description of the rankings for environmental protection require clarification. Catastrophic damage to the environment (Impact 16) includes effects spread over a wide area that are irreversible or require several years to reverse. The example suggests that groundwater contamination above drinking water standards be termed Impact 16 (catastrophic damage). The definitions and example do not seem to differentiate between a dilute plume, most of which is below or only slightly above drinking water standards, and one that greatly exceeds standards and is likely to significantly degrade the resource for many years into the future. We suggest a more graded approach, similar to the one used for public health impacts: catastrophic damage to the resource, excessive contamination of the resource above standards and moderate to lowlevel contamination of the resource.

General Comments:

- BNL used a team to arrive at the actual rankings. The team consisted of BNL staff involved in the EM-30/40/60 Programs, staff from your office, and BNL staff who have been involved in the EH risk ranking activities over the past four years. We feel that this process has resulted in a consistent ranking of BNL activities. 
- While we recognize and support EM's need to use risk assessment as an integral part of overall risk management for the DOE complex, we are concerned that too much emphasis will be placed on numerical values that are intercompared across the DOE sites. While the system adapted by EM is a useful tool, especially for internal ranking at a specific site, the subjectivity of the ranking system and inability to account for other site-specific factors, makes it of questionable value in determining relative priority between activities at different sites, i.e., this is simply a tool and should not be the ultimate factor in risk management decisions.

If you have any questions, please do not hesitate to contact me.

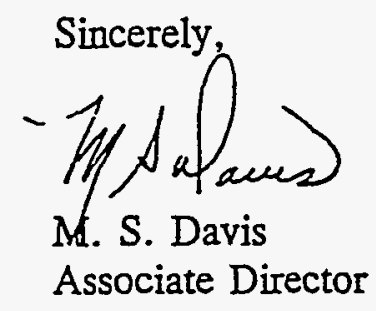

$k r$

Enclosures

c: J. DiNicola (w/o enclosure)

M. Fallier (w/o enclosure)

A. Harvey . (with enclosure)

R. Howe (w/o enclosure)

P. Kwaschyn (w/o enclosure)

A. Meinhold (w/o enclosure)

S. Morris (w/o enclosure)

G. Penny (w/o enclosure)

C. Polanish (w/o enclosure) 
APPENDIX 4. INCORPORATION OF "SPRAY AERATION" INTO ADS 2310 RISK DATA SHEETS 


\section{BROOKHAVEN NATIONAL LABORATORY \\ OFFICE OF ENVIRONMENTAL RESTORATION}

\section{MEMOR A N D U M}

DATE: $\quad$ May 5, 1995

TO: $\quad$ Gail Penny

FROM: Bill Gunther $B 6$

SUBJECT: Incorporation of "Spray Aeration" into ADS 2310 Risk Data Sheets

The scoring process for the Risk Data Sheets originally assumed that the Spray Aeration Removal Action (RA V) was included in Operable Unit I. The ADS 2310 Risk Data Sheet was driven by RA III, Cesspools. Based on today's request, we have re-scored ADS 2310 based on the assumption that it includes RA V. This results in the following scores for ADS 2310:

Inherent Worker Risk:

Environmental Effect:

Social/Cultural, etc:

Public Health and Safety:

Site Personnel Safety and Health:

Compliance:

Mission Impact:

Cost-Effective Management:

Environmental Protection;
$3 C$, marginal, medium likelihood

3C, minor to moderate, medium likelihood

$2 \mathrm{~A}$, significant, very high likelihood (known contaminated ground water plum)

2B/3D; (similar to OU III groundwater issue)

$7 \mathrm{D} / \mathrm{TD}$; (consistent with OU I and OU V)

$8 \mathrm{~A} / 10 \mathrm{C}$; (consistent with all OUs)

13B/13D; (public outcry concern as per OU III)

15B; (consistent with OU I, III, and V)

17A/18C; (consistent with OU I, III, and V)

As you can see, the impact of off-site contamination on the scoring is significant. If additional information is required, please let me know.

c:

R. Howe

A. Meinhold

S. Morris

File-Risk Priority Scoring System 